\title{
Experimentações com resíduo da juçara por meio do MDD e das práticas de correspondência
}

\author{
Caroline Pedraça Santos ${ }^{1}$; \\ Raquel Gomes Noronha2; \\ Denilson Moreira Santos ${ }^{3}$
}

\begin{abstract}
resumo:
Este artigo apresenta o relato de experiência vivenciada durante a pesquisa de experimentação com resíduos de juçara (Euterpe Olerace), por meio do Material Driven Design (MDD) e das práticas de correspondência, realizada com produtores de adubo do Maracanã, bairro de São Luís - MA. O experimento reuniu conhecimentos técnicos, científicos e subjetivos gerados no processo de preparo de um novo compósito constituído de caroços e fibras de juçara e resina de amido. Apresentando desde o momento de aproximação com os produtores até o processo de produção de amostras, tendo como resultado desse encontro de saberes técnicos e tácitos, a produção de pequenos vasos biodegradáveis.
\end{abstract}

palavras-chave:

MDD, experimentação, correspondência, juçara. 


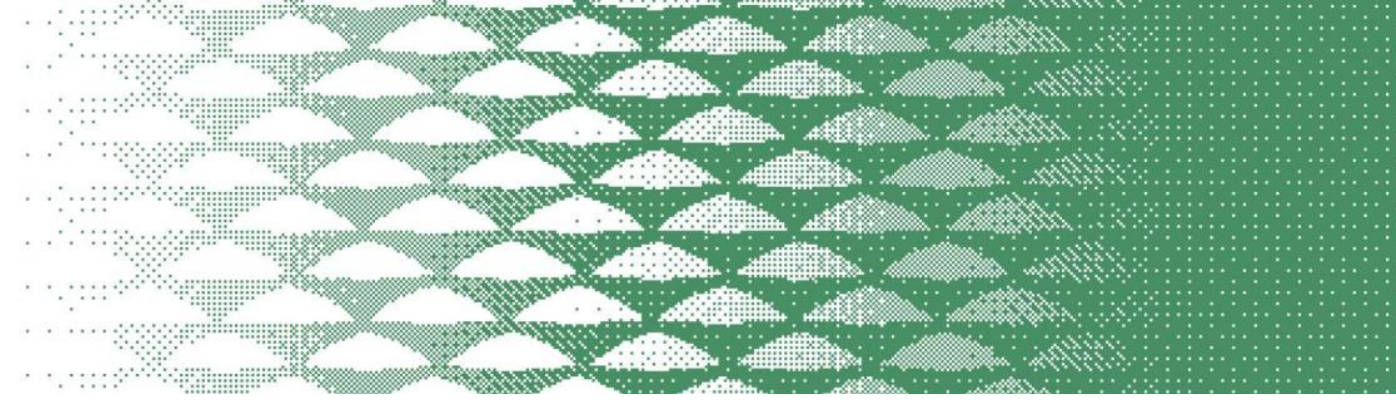

\section{Introdução}

O Maracanã é um bairro localizado na cidade de São Luís, com forte tradição na produção e consumo do fruto da Euterpe Olerace, uma palmeira presente em diversos estados das regiões Norte e Nordeste. As nomenclaturas utilizadas para designá-la variam de um lugar para o outro. Na literatura científica, a palmeira Euterpe Oleracea, predominante em toda região amazônica, é mais conhecida como açaizeiro. Enquanto que a palmeira Euterpe Edulis, nativa da Mata Atlântica do Brasil, é mais conhecida como Juçareira (MARÇAL et al., 2015, p. 693). Adotaremos neste artigo, a nomenclatura juçara, como o fruto é conhecido no Maracanã, local desta pesquisa.

O caroço e a fibra resultantes da extração da polpa da juçara correspondem ao endocarpo e representam 73,46\% do peso da fruta (OLIVEIRA et al, 2002, p. 4). Considerando que a produção anual no Brasil ultrapassa as 221 mil toneladas, tem-se, aproximadamente, 161 mil toneladas de resíduos. Neste contexto, o estado do Maranhão se mostra o terceiro produtor de juçara do Brasil com uma produção de mais de 12 mil toneladas correspondem aos resíduos do fruto.

Pesquisas sobre utilização de fibras naturais na composição de novos materiais apontam para o baixo custo, baixa toxidade e baixo consumo energético, apresentando aspectos ecológicos e sociais positivos. Os estudos realizados com os resíduos de juçara, em específico, demonstraram uma resistência às temperaturas superiores a $150^{\circ} \mathrm{C}$, níveis de aquecimento alcançado na moldagem de material polimérico, ou seja, esses resíduos podem ser utilizados na indústria de embalagem (MARTINS, MATTOSO e PESSOA, 2009, p. 1156). Em outra pesquisa, Mesquita et al (2018, p. 650) verificaram a viabilidade da sua utilização na fabricação de painéis aglomerados. Tais pesquisas indicam que é possível utilizar industrialmente os resíduos de açaí.

Santos e Noronha (2021) realizaram uma Revisão Sistemática de Literatura (RSL) sobre os tipos de processo de utilização dos resíduos da juçara na composição de novo materiais e verificaram que os estudos realizados apresentavam testes feitos em laboratório, mas não envolviam a própria comunidade extratora de juçara na produção de novos materiais. As pesquisadoras puderam observar que os estudos encontrados excluem a comunidade tanto dos processos de pesquisa, quanto dos processos que visam a beneficiamento desses resíduos.

Por outro lado, para além das propriedades que podem ser mensuráveis através de testes em laboratório, as qualidades vêm "da experiência de uma vida de trabalho com o material. Esse é um conhecimento nascido da percepção sensorial e do engajamento prático" (INGOLD, 2015, não paginado). Neste sentido, além dos experimentos em ambiente controlado, o conhecimento tácito da comunidade sobre a juçara pode ser extremamente enriquecedor para o design, considerando a importância de se desenvolver um novo material em colaboração com a comunidade. Além disso, a realização de métodos controlados com a utilização de processos altamente complexos e maquinários de custo financeiro elevado podem não ser viáveis dentro da realidade local do Maracanã.

Para se chegar a este objetivo utilizamos o Material Driven Design (MDD), um método do design que abrange informações cientificas e subjetivas em processos de descoberta de novos produtos e materiais (KARANA et al, 2015). O método parte do pressuposto de que o conceito do produto gerado deve estar diretamente associado ao conceito do material, acrescentando a experiencia sensorial às suas etapas de pesquisa. Desta maneira, considerou-se as possíveis utilizações dos resíduos gerados após o despolpamento do fruto com a proposição de novos materiais, buscando a valorização da cultura tangível (resíduos) e intangível (conhecimento tácito) da comunidade envolvida em um processo colaborativo como nos propõe Spinuzzi (2005, p. 164). 


\section{Método de pesquisa}

Trata-se de uma pesquisa qualitativa, na qual se buscou compreender a produção e utilização dos resíduos da juçara dentro do contexto cultural da comunidade do Maracanã através do resgate dos "significados atribuídos pelos sujeitos ao objeto que está sendo estudado" (GIL, 1999, p. 15). Além disso, trata-se de um assunto ainda pouco conhecido, do qual se objetivou a aproximação sobre conceitos e ideias podendo ser caracterizada como pesquisa exploratória (op.cit, p.27).

A pesquisa também é compreendida como um experimento social de design, pois com base em diálogo, implica numa exploração colaborativa projetada através de atividades de prototipagem e construção de percurso conjunto, na qual o design deve reconhecer sua dependência de um conjunto complexo de competências localizadas em diferentes organizações das partes interessadas (BINDER et al, 2015, p. 167).

Os vínculos com a comunidade foram estabelecidos através das práticas de correspondência que, segundo Ingold (2016), se constroem na ideia de trabalhar "com", ou seja, os atores não são meros aditivos, são contrapontos que ao responderem um ao outro se correspondem. Portanto, é um "processo pelo qual seres ou coisas literalmente se respondem ao longo do tempo, como por exemplo, no trocar de letras ou palavras em conversas ou mesmo de mãos dadas" (INGOLD, p. 8, 2016, tradução nossa).

Como método, utilizamos o Material Driven Design (MDD) que abrange também o estudo das propriedades técnicas e as investigações de significado com os seus usuários, mas difere de outros processos mais usuais de pesquisa material, pois inclui a etapa relacionada ao contato sensorial com o material promovendo experiências de moldagem (KARANA et al, 2015). Este contato tátil está diretamente relacionado ao conhecimento narrativo e ao fluxo dos materiais das práticas de correspondências.

O método prevê a criação de novos compósitos a partir de materiais classificados em três cenários distintos. No primeiro cenário, o material é relativamente conhecido com uma amostra totalmente desenvolvida, ou seja, um material já é conhecido no mercado com o qual o designer busca descobrir novas áreas de aplicação. No segundo cenário, o material é relativamente desconhecido e possui uma amostra totalmente desenvolvida, sobre a qual o designer pretende estudar suas áreas de aplicação e os significados que podem ser introduzidos por ele. E no terceiro cenário trata-se de uma proposta de material semidesenvolvida ou amostras exploratórias, sobre as quais se pretende definir propriedades e áreas de aplicação a partir da obtenção de experiências e significados de seus usuários (op.cit, p. 39).

Neste caso, o resíduo de juçara é um material ainda pouco explorado no campo do design no que se refere às propriedades técnicas, significados e qualidades percebidas por aqueles que o manuseiam. Por esses fatores podemos classificá-lo no terceiro cenário, tornando-se viável a aplicação do MDD para este estudo.

\subsection{Etapas do MDD}

O Material Driven Design (MDD) abrange processos de desenvolvimento de materiais já consagrados e relacionados às propriedades materiais oferecidas por testes em laboratório e às pesquisas de significados e inclui a experimentação e análise de sensações e percepções originadas através do contato direto e sensorial com o material. Desse modo, o designer é capaz de caracterizar o material técnica e experimentalmente, identificando sua aplicação única em contraste com outros materiais (KARANA et al, 2015, p. 41). Para isso, o processo oferece quatro fases para geração dos novos produtos. 


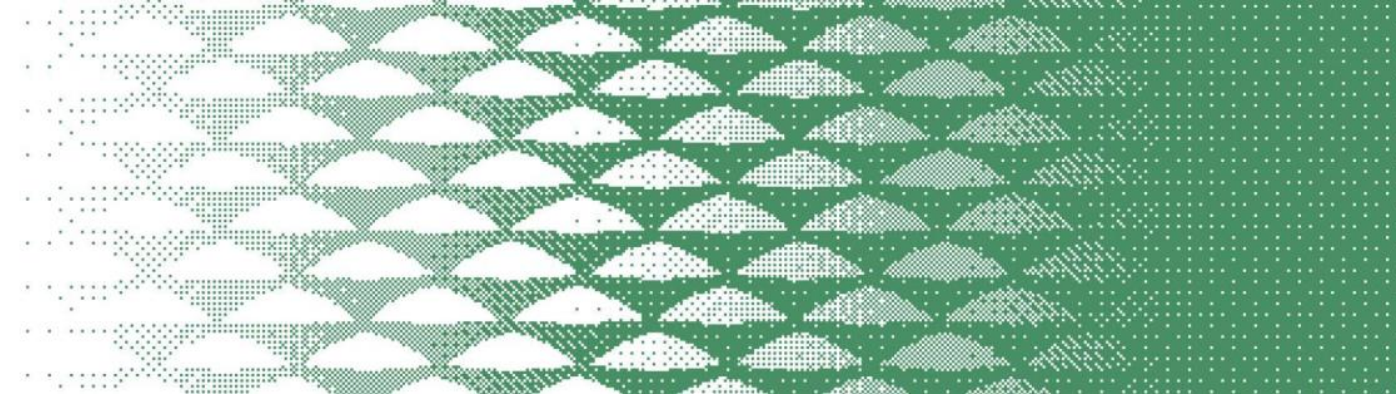

A primeira fase é reunir todas as informações técnicas e subjetivas já conhecidas sobre o material a ser estudado, podendo haver testes em laboratório e a realização de análise de qualidades percebidas através do toque/manuseio. Sendo assim, envolve tanto a caracterização técnica quanto experiencial com o material. Pode haver ainda a criação de um benchmarking para posicionar o material entre seus semelhantes ou alternativos, com identificação das possíveis áreas de utilização. Análises de significado também podem ser realizadas. Destacando que essas atividades não devem ocorrer, obrigatoriamente na ordem apresentada, pelo contrário, devem ter uma abordagem simultânea para criar sinergia e nutrir uma à outra (op.cit, p.41).

A fase 2 oferece a criação de uma visão de experiência material. Através do benchmarking criado na etapa anterior, o designer verifica o que permaneceu constante ao longo dos anos e o que mudou em termos de valores, significados e experiencia material. Com isso é possível construir o Materials Experience Vision e acomodar diversas declarações que podem ser interpretativas e a partir disso propor um caminho visionário de aplicações futuras para o material. Esta etapa deve ser desenvolvida no aprofundamento de fatores subjetivos relacionados ao material (op.cit, p. 42).

A fase 3 envolve a incorporação do Meaning Driven Materials Selection (MDMS) ao método. Nesta etapa pode haver a manifestação de padrões de experiências materiais e o designer pode se familiarizar com os aspectos-chave do material como a forma, o tipo de usuário, a fabricação e os processos. Com base em perguntas feitas a um determinado grupo, as respostas são analisadas qualitativa e quantitativamente, gerando uma análise mais aprofundada sobre a relação entre propriedade e significado (op.cit, p.44).

$\mathrm{Na}$ etapa 4 podem ser criados novos conceitos de material e produto, desde que o conceito do produto esteja associado ao conceito material. É uma etapa de experimentação, onde o designer fica livre para brincar com material, utilizar diferentes resinas, por exemplo, e verificar sua flexibilidade para alcançar as qualidades estéticas desejáveis (op.cit, p.42). Sendo importante destacar que não é necessário percorrer as fases 2 e 3 para realizar a etapa 4 . Com as informações obtidas na etapa 1 é possível partir diretamente para as experimentações da etapa 4 e ao final desta etapa, os materiais mais promissores devem ser usados para a criação de um conceito de produto.

O objetivo do MMD é desenvolver produtos com foco no material utilizado. Neste sentido, Karana et al (2015, p.47) explicam que a identificação do melhor compósito deve ser realizada com base em critérios a serem atendidos pelo material como, por exemplo, características ligadas ao meio ambiente, ao desempenho, ao significado, etc. Aquele que melhor atender a esses critérios deve ser desenvolvido.

\subsection{Adaptação do MDD ao contexto cultural local}

O resíduo da juçara é um material que ainda não apresenta significados e experiências sensoriais anteriormente estudados, o que tornou a fase 2 e 3 dispensáveis para a presente pesquisa. Todas as propriedades técnicas dos resíduos da juçara e outros experimentos disponíveis em literatura foram reunidos e analisados. Essas atividades estavam relacionadas a fase 1 do MDD.

Para a realização da fase 4 , o método sugere a criação de grupos focais para a experimentação material. No entanto, contextualizando a pesquisa no Maracanã e com o casal com quem desenvolvemos o material e suas relações com os resíduos da juçara, propomo-nos iniciar a fase 4, com o desenvolvimento de oficinas para o manuseio dos resíduos.

Para melhor compreensão apresentamos abaixo, o quadro 1 com o resumo das fases do MDD adaptadas ao contexto da pesquisa em epigrafe: 


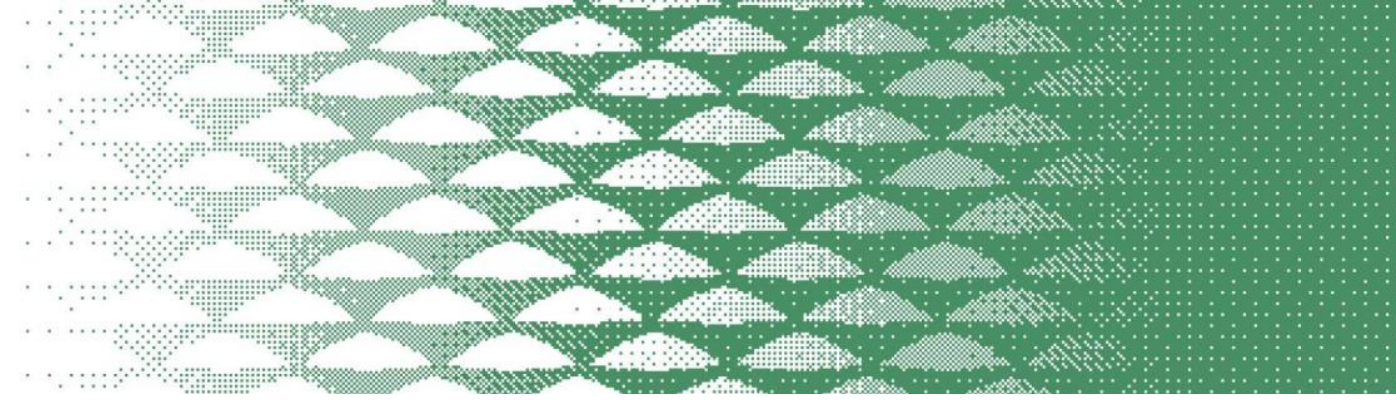

nos traziam perspectivas diferentes sobre os resíduos vegetais, incluindo caroços e restos de planta, fomos construindo uma teia de conhecimentos que veio a sustentar todo o restante dos experimentos.

\subsection{MDD: correspondências e experimentação material}

Diante da Pandemia do COVID 19, as atividades estavam suspensas e os experimentos foram postergados para quando fosse possível ter contato social. Após primeiro lockdown, em maio de 2020, quando já nos sentíamos mais seguros para iniciar um encontro presencial desde que seguíssemos as devidas orientações de segurança, como uso de máscara e distanciamento social, a máquina de triturar adubo do casal estava inativa por problemas técnicos. Aguardamos até janeiro de 2021, e como a máquina continuava sem funcionar, foi necessário percorrer outra ordem de etapas na pesquisa.

O MDD deixa livre a ordem de etapa pelas quais podemos proceder com a pesquisa e propõem que elas sejam estabelecidas de acordo com o tipo de material e a maneira que for viável experimentalo (KARANA et al, 2015, p.42). Sendo assim, após revisão de literatura com a coleta das propriedades técnicas dos resíduos e a compreensão do que era possível realizar com esse material, decidimos selecionar a resina que iriamos utilizar nos experimentos.

Com base nas pesquisas encontradas, a resina de mamona era a mais utilizada. Esse mesmo material foi sugerido pelo Edmilson. Porém, não seria facilmente encontrado na cidade de São Luís, teria que ser comprado pela internet, fugindo as premissas de sustentabilidade, ampliando a questão da logística. Sendo assim, nos concentramos em realizar o experimento com base em materiais que pudessem ser encontrados em São Luís ou que pudessem ser facilmente produzidos pela comunidade. Foi então que Edmilson sugeriu a resina feita a partir da mandioca, material semelhante ao que estava sendo pesquisado na Universidade Federal do Maranhão.

Vale a pena lembrar que o MDD aborda os materiais em seus mais diversos aspectos, desde de suas propriedades técnicas, seus aspectos sensoriais e suas memórias. Neste contexto, todas as experiências e informações trazidas por aqueles que estavam envolvidos no processo estavam sendo consideradas sob a filosofia das práticas de correspondência, por meio da qual o conhecimento é construído a partir do contar de histórias. Era exatamente isso que estávamos fazendo, nessas trocas de saberes íamos tecendo uma nova história para realizar experimentos inovadores que não se originassem exclusivamente de bases técnicas, mas que pudessem ser construídos também através das diferentes percepções e experiências materiais.

Por esse motivo, elegemos o amido de milho como o material a ser utilizado nas primeiras amostras. Consideramos a informação inicial de Edmilson e seguimos com base nas pesquisas que já vinham sendo realizadas na UFMA, e assim teríamos aporte técnico. Decidimos iniciar os primeiros testes em laboratório com o auxílio do Engenheiro Químico Adones Almeida Rocha, vinculado ao Laboratório de Engenharia de Produtos e Processos em Biorrecursos (LEPPbio) do Departamento de Engenharia Química da UFMA e que havia realizado pesquisas com resina de amido de milho durante a sua graduação.

Para a produção da resina de amido de milho, utilizamos dois artigos como referencias: Obtenção de Nanocelulose da fibra de coco verde e incorporação em filmes biodegradáveis de amido plastificados com Glicerol de Machado et. al., (2014) e Bioactive films based on babassu mesocarp flour and starch de Maniglia et. al., (2017)-. A partir desses estudos foi possível estabelecer os materiais e as quantidades que seriam utilizadas inicialmente. De acordo com Rocha (2021), os valores apresentados nos dois estudos foram adaptados de acordo com a necessidade de elaborar um material mais rígido e espesso. O mais adequado seria utilizar uma metodologia consolidada para tal, mas na experiencia os valores foram feitos de acordo com os protocolos do Laboratório de Engenharia de Produtos e Processos em Biorrecursos (LEPPbio) (ROCHA, 2021). 


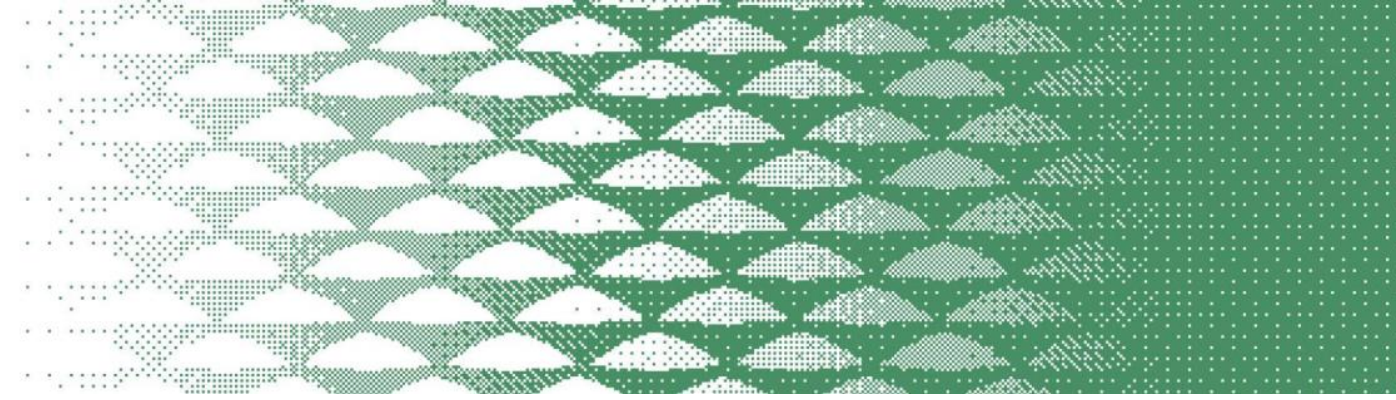

Além de água, foram utilizados três materiais: amido de milho, glicerol e ácido acético 5\% misturados aos resíduos de caroços de juçara. Uma parte desse resíduo foi triturado no pilão do laboratório de cerâmica e outra parte era adubo de palmeira. A mistura ficou no Turrax (Fisaton, modelo 67 , Brasil) por 30min sem aquecimento, depois mais $30 \mathrm{~min}$ com aquecimento. O material resultou em 3 amostras: uma deixada na estufa a $90^{\circ} \mathrm{C}$ por $24 \mathrm{~h}$ que ressecou, grudando no recipiente, e não pode ser retirada do recipiente. E mais duas amostras que foram levadas para o ambiente residencial, para secar na varanda, simulando uma situação da vivência cotidiana no Maracanã.

Obtivemos resultados satisfatórios com as amostras produzidas em laboratório e que secaram em casa em temperatura ambiente. Visivelmente a que aparentava ter melhor aspecto estético e resistência era a peça feita com caroços triturados no pilão no laboratório de cerâmica do curso de Design. Após os testes realizados em laboratório, onde foi possível testar a resina e analisar as primeiras peças, a máquina de adubo voltou a funcionar e iniciamos os testes com o próprio adubo. Levamos o material para ser reproduzido em casa, em semelhança ao que viria a acontecer quando pudemos nos reunir Keila e Edmilson. Nesta fase, já não podíamos contar com os equipamentos e materiais do laboratório.

Quadro 2 - Materiais do experimento em laboratório x materiais do experimento em casa

\begin{tabular}{|l|l|}
\hline Laboratório & Caseiro \\
\hline Turrax & Mexendo com o auxílio de uma colher de inox \\
\hline Turrax com temperatura máxima $90^{\circ} \mathrm{C}$ & Fogão 4 bocas (na menor boca, em fogo baixo) \\
\hline Água ionizada & Água de torneira - salobra \\
\hline Glicerol puro & Glicerol manipulado \\
\hline Ácido acético 5\% & Ácido acético 5\% \\
\hline Amido de milho & Amido de milho \\
\hline
\end{tabular}

Além do adubo, utilizamos caroços que nós trituramos num pequeno pilão metálico e água de torneira. As amostras resultantes deste primeiro experimento caseiro, tanto com caroços triturados, quanto com adubo, para nossa surpresa, estavam mofando e entrando em estado de putrefação. Vale a pena destacar que esse momento coincidiu com o início do período chuvoso. Além disso, outros dois fatores poderiam estar influenciando no apodrecimento das peças: a água e a temperatura da chama. A água utilizada em laboratório era ionizada e a água utilizada em casa, era de torneira, oriunda de poços artesiano de águas salobras. Quanto à temperatura, o equipamento utilizado em laboratório atingia o máximo de $90^{\circ} \mathrm{C}$, e a temperatura do fogão poderia ultrapassar isso. Percebemos que, em casa, a resina atingia rapidamente o ponto de fervura.

Vale a pena destacar que os resíduos utilizados nos primeiros testes possuíam as seguintes características: o adubo de palmeira produzido em uma época sem chuva, bastante seco. E o caroço no laboratório de cerâmica, sobre o qual não sabemos se foi seco na estufa ou ao ar livre. Desta maneira, com o apodrecimento das peças, todo contato prévio que havíamos estabelecidos com esse material, de um material resistente a mofos e bichos estava se desfazendo em função do resultado das amostras que estávamos obtendo.

Ao compartilharmos o resultado com Edmílson, pelo WhatsApp, ele explicou que os resíduos triturados na máquina de adubo não haviam completado seu ciclo de secagem por causa das fortes chuvas. Eles estavam úmidos, pois não puderam ser expostos ao sol e não receberam a incidência de raios solares e nem a passagem e ventilação necessários. Ele afirmou ainda que a presença de mofo seria extremamente benéfica para a opção de produzirmos um cachepô, uma espécie de vasinho biodegradável onde a planta é inserida servindo-lhe de adubo ao se decompor. Essa possibilidade de uso foi 


\section{JOP \\ DESIGN \\ de Pós-Graduação em Design - UFMA}

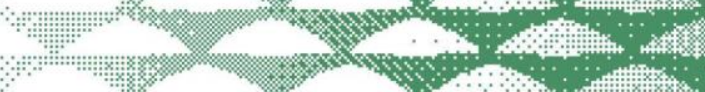

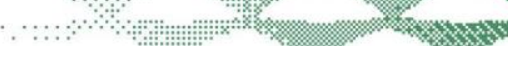

Keywords: mdd; experimentation; correspondence; juçara.

\section{Referências bibliográficas}

BINDER, T., Brandt, E., Ehn, P. and Halse, J. (2015) Democratic design experiments: between parliament and laboratory, CoDesign: International Journal of CoCreation in Design and the Arts, 2015.

GIL, A. C. Métodos e técnicas de pesquisa social. São Paulo: Atlas, 1999.

INGOLD, Tim, 1948 - Estar vivo: ensaios sobre movimento, conhecimento e

descrição / Tim Ingold; tradução de Fábio Creder. - Petrópolis, RJ: Vozes, 2015. - (Coleção Antropologia). E-book.

INGOLD, Tim. On human correspondence. in Journal Of The Royal Anthropological Institute, Wiley, [S.L.], v. 23, n. 1, p. 9-27, dez. 2016

KARANA, Elvin et al. Material Driven Design (MDD): a method to design for material experiences. International Journal Of Design, [s. ], v. 9, n. 2, p. 35-54, 2015.

MANIGLIA, Bianca C. et al. Bioactive films based on babassu mesocarp flour and starch.

Food Hydrocolloids, Elsevier BV, [S.L.], v. 70, p. 383-391, set. 2017

MACHADO, Bruna A. S. et al. Obtenção de nanocelulose da fibra de coco verde e incorporação em filmes biodegradáveis de amido plastificados com glicerol. Química Nova, GN1 Genesis Network, [S.L.], p. 1276-1282, 01 jul. 2014.

MARÇAL, Tiago de Souza et al. Correlações genéticas e análise de trilha para caracteres de fruto da palmeira juçara. Revista Brasileira de Fruticultura, FapUNIFESP (SciELO), [s.I.], v. 37, n. 3, p.692-698, set. 2015.

MARTINS, Maria Alice; MATTOSO, Luiz Henrique Capparelli; PESSOA, José Dalton Cruz. Comportamento térmico e caracterização morfológica das fibras de mesocarpo e caroço do açaí (Euterpe oleracea Mart.). Revista Brasileira de Fruticultura, FapUNIFESP (SciELO), [s.I.], v. 31, n. 4, p.1150-1157, dez. 2009.

MESQUITA, Antonio de Lima et al. Eco-particleboard manufactured from chemically treated fibrous vascular tissue of acai ( Euterpe oleracea Mart. ) Fruit: a new alternative for the particleboard industry with its potential application in civil construction and furniture. Industrial Crops And Products, Elsevier BV, [S.L.], v. 112, p. 644-651, fev. 2018.

OLIVEIRA, Maria do Socorro Padilha de et al. Cultivo do Açaizeiro para Produção de Frutos. Circular Técnica 26, EMBRAPA, Ministério da Agricultura, Pecuária e Abastecimento, Belém, PA, v. 26, p.1-18, jun. 2002.

ROCHA, Adones Almeida. Artigos como Base para Metodologia. [mensagem pessoal] Mensagem recebida por: <carolpedraca@gmail.com>. em: 13 maio 2021.

SANTOS, Caroline Pedraça; NORONHA, Raquel Gomes. Pesquisa colaborativa em design para aproveitamento de resíduos de açaí em comunidades locais: delimitação do estado da arte.

Relacult - Revista Latino-Americana de Estudos em Cultura e Sociedade, [S.L.], v. 
7, p. 1-16, 28 fev. 2021. Quadrimestral. Centro Latino-Americano de Estudos em Cultura CLAEC.

SPLABOR. Peneiras Granulométricas ou Tamis - Saiba como utilizar. 2018. Disponível em: http://www.splabor.com.br/blog/peneiras/peneiras-granulometricas/. Acesso em: 02 ago. 2021.

SPINUZZI, Clay. The methodology of participatory design. Technical Communication, v. 52, n. ${ }^{\circ}$ 2, p. 163-174, maio 2005. 